\title{
EFISIENSI DENGAN KONVERSI SATUAN HARGA TINTA RP/GRAM MENJADI RP/SHEET PADA TINTA FLEKSO
}

\author{
Endang Yuniarti ${ }^{1}$, Risya Kusna Putri \\ Teknik Grafika, Jurusan Teknik Grafika dan Penerbitan, Politeknik Negeri Jakarta \\ Jalan Prof. Dr. G. A. Siwabessy, Kampus UI, Depok 16425 \\ e-mail : ${ }^{1}$ endang.yuniarti@grafika.pnj.ac.id
}

\begin{abstract}
There agreement between ink companies and printing companies that is the ink company will supply printing ink according to the needs of the printing company and if there is excess ink, it will be requested. Ink returns according to company data reach 50 to $80 \%$. The problem that arises is the problem of ink that will become junk, and the impact is inefficiency. The purpose of this study is to test the selling price unit of RP/KG ink to become RP/Sheet. The method used in this study is the calculation of BM area using Automatic Cad and is calculated using ink in $\mathrm{gr} / \mathrm{m}^{2}$ units which is then used to be gr/sheet units and converted again to the unit price, which is $R$ p/sheet. The object of research is KKG instant noodles. This research resulted in the conversion of black and white price units used in this instant noodle product with units of Rp/gr indicating a more expensive price of Rp.49,806 per gram while with units of Rp/sheet of Rp17,34 per sheet. So by using units of Rp/sheet, give the ink company to estimate when sending ink so that it can be minimized from printing companies.
\end{abstract}

Key words: Price, Carton packaging, Rp/sheet

\begin{abstract}
ABSTRAK
Terdapat salah satu kesepatan antara perusahaan tinta dengan perusahaan percetakan. Kesepatan itu adalah perusahaan tinta akan menyuplai tinta cetak sesuai dengan kebutuhan perusahaan percetakan dan jika tinta berlebih, akan dikembalikan. Pengembalian tinta menurut data perusahaan mencapai 50 hingga 80\%. Permasalahan yang muncul adalah pengembalian tinta akan menjadi sampah (waste), sehingga biaya menjadi tidak efisien. Tujuan dari penelitian ini adalah mengkonversi satuan harga jual tinta dari RP/KG menjadi RP/Sheet. Metode yang digunakan dalam penelitian ini adalah perhitungan luas area BM menggunakan Auto Cad dan dihitung pemakaian tinta dengan menggunakan satuan $\mathrm{gr} / \mathrm{m}^{2}$ yang selanjutnya dikonversi menjadi satuan $\mathrm{gr} / \mathrm{sheet}$ dan konversi lagi dengan satuan harga, yaitu Rp/sheet. Obyek penelitian adalah KKG mie instan. Penelitian ini menghasilkan konversi satuan harga pemakaian tinta baik merah dan hitam yang digunakan pada produk mie instan ini dengan satuan Rp/gr menunjukan harga yang lebih mahal sebesar RP 49,806 per gram sedangkan dengan satuan Rp/sheet sebesar Rp 17,34 per sheet. Jadi dengan menggunakan satuan Rp/sheet memudahkan perusahaan tinta untuk melakukan estimasi saat mengirimkan tinta sehingga pengembalian tinta dari perusahaan percetakan dapat diminimalisir.
\end{abstract}

Kata kunci: Harga Tinta, Kemasan Karton, Rp/lembar

\section{PENDAHULUAN}

Penggunaan mesin cetak dengan teknik fleksografi mengalami perkembangan yang sangat pesat di dunia percetakan. Di akhir tahun 70-an fleksografi hanya memiliki share $10 \%$ dengan pertumbuhan per tahun $4 \%$ (offset 52 $\%$, rotogravure $28 \%$ ) namun di tahun 2006 fleksografi memiliki market share $28 \%$ (offset turun menjadi $45 \%$ dan rotogravure turun menjadi $20 \%$ ) dengan pertumbuhan per tahun tetap 4 \%. Diperkirakan 5 tahun yang akan datang fleksografi akan memiliki market share $33 \%$ sedangkan cetak offset turun menjadi $35 \%$ dan rotogravure menjadi $15 \%$ (Wasono, dkk, 2008).

Salah satu produk cetak yang menggunakan teknik cetak fleksografi adalah kemasan karton gelombang (KKG). Tinta yang digunakan pada teknik cetak ini adalah tinta cair yang 
berbasis air. Seperti yang telah diketahui, bahwa teknik cetak flekso termasuk dalah teknik cetak tinggi, namun acuan cetaknya menggunakan rubber atau sejenisnya. Pada teknik cetak tinggi, acuan cetak memiliki karakteristik, yaitu bagian image (Bagian Mencetak = BM) lebih tinggi dari bagian non-image (Bagian Tidak Mencetak $=$ BTM).

Studi kasus pada penelitian ini adalah kasus yang terjadi pada perusahaan tinta. Produsen atau perusahaan tinta bertindak sebagai supplier perusahaan percetakan. Terdapat salah satu kesepatan antara perusahaan tinta dengan perusahaan percetakan. Kesepatan itu adalah perusahaan tinta akan menyuplai tinta cetak sesuai dengan kebutuhan perusahaan percetakan dan jika tinta berlebih, akan dikembalikan.

Kesepakatan inilah yang mengakibatkan perusahaan tinta merasa dirugikan. Tinta yang dikembalikan oleh perusahaan percetakan sudah tercampur dengan bahan pengecer sehingga tinta tidak bisa disimpan lama dan kualitas tinta menurun jika tidak segera digunakan. Pengembalian tinta menurut data perusahaan mencapai 50 hingga $80 \%$. Permasalahan yang muncul adalah pengembalian tinta akan menjadi sampah (waste) jika tidak segera digunakan karena masa simpan yang makin cepat bila sudah dicampur dengan bahan pengencer sehingga diharapkan pengembalian tinta dari perusahaan percetakan dapat diminimalisir.

Permintaan akan kebutuhan tinta sulit diprediksi oleh perusahaan tinta karena satuannya berupa RP/KG. Penggunaan satuan tersebut kurang bisa mengilustrasikan kebutuhan tinta untuk mencetak BM. Sehingga dibutuhkan satuan yang dapat mengilustasikan kebutuhan tinta tersebut, yaitu dengan menggunakan satuan RP/Sheet. Maka tujuan dari penelitian ini adalah mengkonversi satuan harga jual tinta dari RP/KG menjadi RP/Sheet. Manfaat yang diperoleh dari penelitian ini adalah agar dapat memudahkan perusahaan tinta mengestimasi kebutuhan tinta bagi konsumennya yaitu perusahaan percetakan sehingga pengembalian tinta dapat diminimalisir.

\section{METODE PENELITIAN}

Metode yang digunakan dalam penelitian ini adalah dengan urutan langkah sebagai berikut :

1. Pengambilan sampel

Sampel cetakan yang digunakan adalah KKG yang digunakan sebagai kemasan sekunder mie instan.

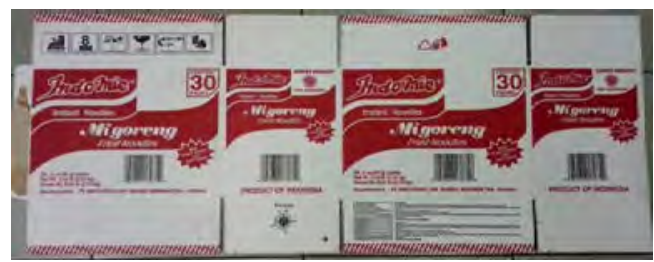

Gambar 1. KKG mie instan

2. Perhitungan luas area BM

Untuk menghitung luas area BM adalah dengan menscan KKG. Berhubung alat scanner memiliki ukuran terbatas makan sampel utuh KKG dipotong pada bagian yang memiliki ukuran BM berbeda.

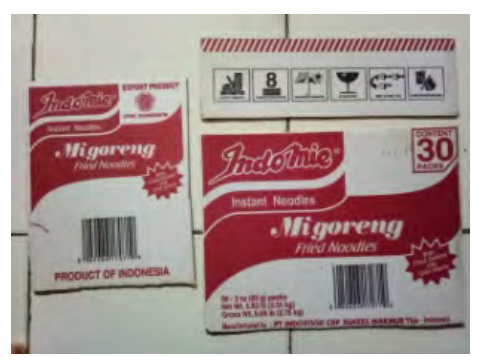

Gambar 2. KKG yang dalam kondisi terpotong

Dengan rincian tahap sebagai berikut:

a. Memotong sampel

b. Menscan potongan sampel

c. Menyimpan file scan dalam bentuk jpeg

d. Menggambar ulang area BM sesuai dengan desain 
e. Mengubah file jpeg menjadi drawing (Auto Cad)

f. Membuka file dengan Auto Cad, pilih bagian BM, cek propertiesnya

g. Menghitung area BM berdasarkan warna

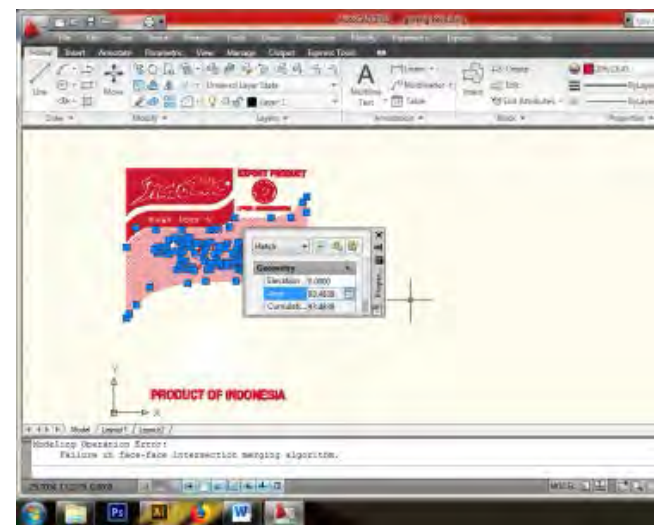

Gambar 3. Penyetelan file properties pada Auto Cad

\section{Estimasi Pemakaian tinta}

Estimasi dilakukan dengan menghitung area BM untuk masing-masing warna. Sehingga diperoleh estimasi pemakaian warna secara keseluruhan.

4. Perhitungan harga tinta

Berdasarkan estimasi kebutuhan tinta maka dapat dihitung harga tinta dalam satuan RP per sheet atau lembar pada produk cetak KKG tersebut.

\section{HASIL dan PEMBAHASAN}

\section{Luas Area BM}

Luas area BM untuk warna Hitam meliputi 4 bagian, yaitu bar code, tanda peringatan, arah mata angin dan uraian teks komposisi nutrisi.

Untuk luas area BM warna Merah terdiri dari 4 (empat) bagian juga, yaitu identitas produk dibagian halaman depan dan samping; tanda perekat dan instruksi cara pembuangan sampahnya.
Tabel 1. Luas area BM hitam

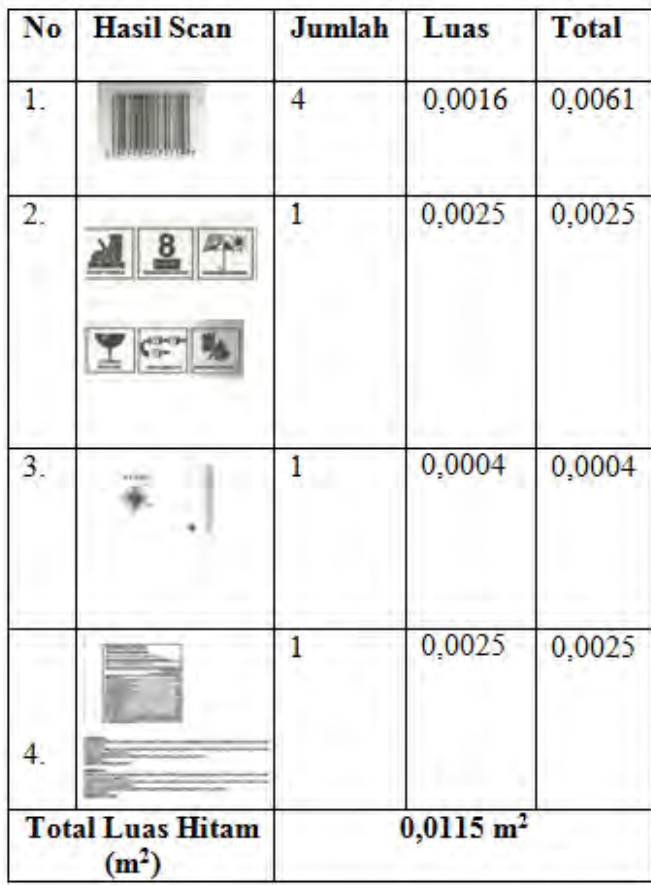

Tabel 2. Luas area BM warna merah

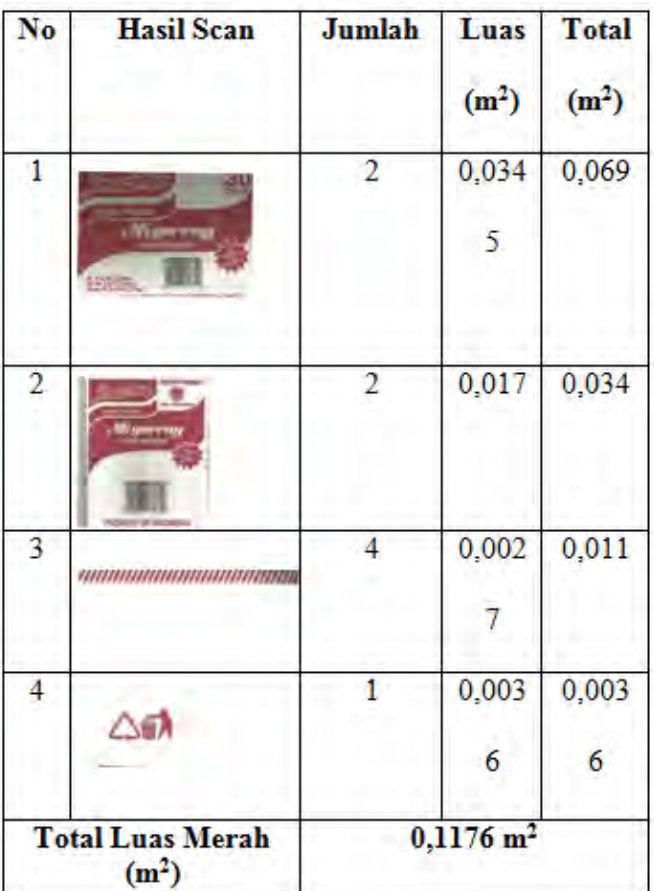

Persentase (\%) luas area cetak dari total luas dimensi KKG, dapat dihitung dengan rumus :

$\%($ Persentase $)=\frac{\text { Total Luas Area BM }}{\text { Total Luas Dimensi Kardus }} \times 100 \%$

Oleh karena itu, luas area cetak KKG mie instan ini menunjukan bahwa warna merah adalah $0,1138 \mathrm{~m}^{2}$ atau 25,98\% 
dari area total KKG dan hitam sebesar $0,0114 \mathrm{~m}^{2}$ atau $2,60 \%$.

Tabel 3. Luas area dan persentase BM

\begin{tabular}{|c|c|c|c|}
\hline Warna & $\begin{array}{c}\text { Kode } \\
\text { Tinta }\end{array}$ & $\begin{array}{c}\text { Luas } \\
\text { Area BM } \\
\mathbf{( m}^{\mathbf{2}} \mathbf{m}\end{array}$ & $\begin{array}{c}\text { Persen } \\
\text { tase Area } \\
\mathbf{B M}\end{array}$ \\
\hline Merah & MP 0082 & 0,1138 & $25,98 \%$ \\
\hline Hitam & MP 0049 & 0,0114 & $2,60 \%$ \\
\hline Total & & 0,1252 & $28,58 \%$ \\
\hline
\end{tabular}

Oleh karena itu, diperoleh perhitungan pemakaian tinta sesuai dengan menggunakan Oktober 2017 dengan oplah $22.500 \mathrm{~m}^{2}$. Perhitungan ini untuk mengetahui nilai penggunaan tinta setiap lembaran cetak pada cetakan tersebut. Dengan menghitung jumlah penyerapan kertas terhadap tinta setiap meter persegi $\left(\mathrm{m}^{2}\right)$, setelah itu menentukan jumlah pemakaian tinta per warna setiap lembar (sheet), dan total pemakaian tinta per lembar (sheet).

\section{Estimasi Pemakaian Tinta}

Untuk mengetahui perkiraan pemakain tinta maka dilakukan estimasi dengan melihat data pemakaian tinta sebelumnya, yaitu pada kemasan KKG mie instan pada oplah 22.500 unit dengan periode bulan oktober 2017. Pemakaian tinta dihitung dengan persamaan sebagai berikut.

a. Pemakaian Tinta Setiap Meter Persegi $\left(\mathrm{gr} / \mathrm{m}^{2}\right)$

$$
\text { Rumus }=\frac{\text { Tinta Dikirim }- \text { Tinta Kembali }}{\text { Oplah } \mathrm{x} \text { Area Cetak }} \times 100 \%
$$

b. Pemakaian tinta (gr/sheet)

$$
\text { Rumus }=\frac{\text { Tinta Dikirim }- \text { Tinta Kembali }}{\text { Oplah }}
$$

Pemakaian tinta menggunakan satuan $\mathrm{gr} / \mathrm{m}^{2}$ membutuhkan lebih banyak tinta sebesar 23,18 $\mathrm{gr} / \mathrm{m}^{2}$ sedangkan jika menggunakan satuan gr/sheet, total pemakaian hitam dan merah pada produk mie instan hanya memakai tinta sebanyak 0,65 gr/sheet.

Oleh karena itu, diperoleh tabel pemakaian tinta sebagai berikut:
Tabel 4. Pemakaian tinta

\begin{tabular}{|l|l|l|l|l|}
\hline Warna & $\begin{array}{l}\text { Tinta } \\
\text { Terkirim } \\
\text { (gr) }\end{array}$ & $\begin{array}{l}\text { Tinta } \\
\text { Kembali } \\
\text { (gr) }\end{array}$ & $\begin{array}{l}\text { Pemakai } \\
\text { an Tinta } \\
\left(\mathbf{g r} / \mathbf{m}^{2}\right)\end{array}$ & $\begin{array}{l}\text { Pemakai } \\
\text { an Tinta } \\
\text { (gr/sheet) }\end{array}$ \\
\hline Merah & 17.700 & 6.970 & 4,19 & 0,48 \\
\hline Hitam & 24.800 & 21.000 & 18,99 & 0,17 \\
\hline Total & 23,18 & 0,65 \\
\hline
\end{tabular}

\section{Perhitungan Harga Tinta}

Perhitungan penentuan harga jual tinta dengan acuan harga tinta perusahaan dengan sistem harga yang diberikan rupiah per $\mathrm{kg}(\mathrm{Rp} / \mathrm{kg})$ menjadi rupiah per sheet (Rp/Sheet). Agar proses perhitungan ini lebih mudah, maka langkah awal yaitu mengubah satuan dari harga/kilogram (kg) menjadi harga/gram (gr).

$$
\text { Rumus }=\frac{\text { Harga Tinta } / \mathrm{kg}}{1000}
$$

Dan untuk menghitung harga tinta setiap warna untuk warna merah dan hitam adalah sebagai berikut:

$$
\text { Rumus }=\text { Harga } \frac{\text { Tinta }}{\mathrm{Gr}} \times \text { Total Pemakaian Tinta }
$$

Jika harga tinta warna merah adalah Rp 28.990 per $\mathrm{kg}$ dan hitam sebesar Rp 20.806 maka dengan menggunakan kedua rumus di atas, dapat diperoleh harga tinta dalam satuan $\mathrm{Rp} /$ sheet seperti yang tertera pada tabel berikut ini.

Tabel 5. Harga tinta

\begin{tabular}{|l|l|l|l|}
\hline Warna & $\begin{array}{l}\text { Harga } \\
(\mathrm{Rp} / \mathrm{kg})\end{array}$ & $\begin{array}{l}\text { Harga } \\
(\mathrm{Rp} / \mathrm{gr})\end{array}$ & $\begin{array}{l}\text { Harga } \\
(\mathrm{Rp} / \text { sheet })\end{array}$ \\
\hline Merah & 28.990 & 28,990 & 13,83 \\
\hline Hitam & 20.806 & 20,806 & 3,51 \\
\hline Total & & 49,806 & 17,34 \\
\hline
\end{tabular}

Berdasarkan tabel di atas, maka harga total pemakaian tinta merah dan hitam jika menggunakan satuan rupiah per berat, yaitu $\mathrm{Rp} / \mathrm{kg}$ atau $\mathrm{Rp} / \mathrm{gr}$ menunjukan harga yang lebih mahal sebesar RP 49,806 per gram sedangkan jika menggunakan satuan Rp/sheet sebesar Rp 17,34 per sheet. 


\section{KESIMPULAN}

Berdasarkan hasil penelitian yang telah dilakukan maka dapat disimpulkan bahwa luas area cetak KKG mie instan ini menunjukan bahwa warna merah adalah $0,1138 \mathrm{~m}^{2}$ atau 25,98\% dari area total KKG dan hitam sebesar 0,0114 $\mathrm{m}^{2}$ atau 2,60\%. Pemakaian tinta menggunakan satuan $\mathrm{gr} / \mathrm{m}^{2}$ membutuhkan lebih banyak tinta sebesar 23,18 $\mathrm{gr} / \mathrm{m}^{2}$ sedangkan jika menggunakan satuan gr/sheet, total pemakaian hitam dan merah pada produk mie instan hanya memakai tinta sebanyak 0,65 gr/sheet. Sehingga konversi satuan harga pemakaian tinta baik merah dan hitam yang digunakan pada produk ini, jika menggunakan satuan rupiah per berat, yaitu $\mathrm{Rp} / \mathrm{kg}$ atau Rp/gr menunjukan harga yang lebih mahal sebesar RP 49,806 per gram sedangkan juka menggunakan satuan Rp/sheet sebesar Rp 17,34 per sheet. Jadi dengan menggunakan satuan $\mathrm{Rp} /$ sheet memudahkan perusahaan tinta untuk melakukan estimasi saat mengirimkan tinta sehingga pengembalian tinta dari perusahaan percetakan dapat diminimalisir.

\section{DAFTAR PUSTAKA}

[1] Beex, L.A.A. dkk. 2009. An Experimental and Computational Study of Laminated Paperboard Creasing and Folding. Netherland: International Journal of Solids and Structures.

[2] Emblem, A., dan Henry Emblem. 2012. Packaging Technology Fundamentals, materials and processes. Cambridge: Woodhead Publishing Limited (buku online, diakses pada 22 Juni 2017)

[3] Iggesund. 1992. Finishing, diakses dari

https://www.iggesund.com/global assets/iggesund-documents/rmpdfer/4.-printing-and-converting- performance/diecutting

and_creasing_en.pdf, pada 21 Juni 2017.

[4] Iggesund. 1992. Stiffness, diakses dari

https://www.iggesund.com/en/kno wledge/the-reference manual/baseboard-physicalproperties/Stiffness/, pada 15 Juni 2017

[5] Irawan. M. 2011. Pengujian Sarana Dan Prasarana Penyimpanan Arsip. Jakarta: ANRI

[6] Hanlon, J. F. 1998. Handbook of Package Engineering (Third Edition). Lancaster: Technomic Publishing Company, Inc.

[7] Huang, H. dkk. 2013. Quasi static analysis of creasing and folding for three Paperboards. Sweden: Mechanics of Materials. Vol 69, Issue 1.

[8] Julianti, Sri. 2014. The Art of Packaging. Jakarta: PT. Gramedia Pustaka Utama.

[9] Kurniawan, Iwan. 2013 Omzet Industri Kemasan Diperkirakan Rp $50 \mathrm{~T}$, diakses dari http://www.neraca.co.id, pada 1 Juli 2017

[10] Muryeti. 2008. Ilmu Bahan Grafika I. Depok: PNJ Press.

[11] Niskanen, Kaarlo. 2012. Mechanics of Paper Products. Stockholm: Innventia $\mathrm{AB}$ (buku online, diakses pada 22 Juni 2017)

[12] Nurminah, Mimi. 2002. Penelitian Sifat Berbagai Bahan Kemasan Plastik dan Kertas serta Pengaruhnya Terhadap Bahan yang Dikemas, diakses dari http://library.usu.ac.id/download/f p/fp-mimi.pdf, pada 1 Juli 2017

[13] Roojen, V. Pepin. 2005. How to Fold (Agile Rabbit Editions). Amsterdam: Pepin Press.

[14] Taylor, M. 2016. Smithers Pira. Diambil kembali dari Carton Opening Force, diakses dari 
Endang Yuniarti dan Risya Kusna Putri, Efisiensi dengan Konversi Satuan...

http://www.smitherspira.com, pada 11 April 2017

[15] Wilson, A Lawrance. 2000. What The Printer Should Know About Paper. 3th Ed. GATF Press 